\title{
Deliberate self-harm: service development in Kettering
}

\author{
Catherine Gordon and Andrew Blewett
}

\begin{abstract}
Services for dellberate self-harm patients in the general hospltal are unsatisfactory in many respects. A survey of activity and quallty in a district general hospltal confirmed recent trends observed elsewhere and highlights areas in which service provision can be improved.
\end{abstract}

High rates of deliberate self-harm (DSH) are a public health problem. A study in Oxford showed rising rates among young women during the late 1980s, and a threefold increase in the proportion due to paracetamol poisoning between 1976 and 1990 (Hawton \& Fagg, 1992). A multicentre European study found a trend of increasing peak age, a declining female to male ratio, and unexplained differences between regions (Platt, 1992). In the year following DSH, 9\% repeat (Hawton \& Fagg, 1992); and suicide rates reach 1.1 to $1.3 \%$ of patients in the three years following an episode of DSH (Owens et al, 1991).

DSH services aimed at treating psychiatric morbidity, preventing recurrence and suicide, and reducing the burden on medical services should be a priority. DSH discharge rates from accident and emergency (A\&E) departments have risen from $10-15 \%$ to $30 \%$ or higher in recent years (Owens, 1990), and assessments may be grossly inadequate (O'Dwyer et al, 1991). Rates of depressive illness in DSH patients vary upwards from 31\% depending on selection factors (Ennis et al, 1989). DSH patients are often said to have 'low' rates of mental illness although this figure implies a large volume of potentially missed morbidity, in spite of evidence that relatively untrained A\&E staff admit patients with a higher risk of mental illness (Owens \& Jones, 1988).

\section{The study}

Rockingham Forest NHS Trust offers a consultation liaison psychiatry (CLP) service to the general hospital in Kettering. DSH is a key area for development. This study was designed to assess projected need and audit baselines, and to examine DSH related activity in the accident and emergency department (A\&E), general hospital wards, and throughput to the general psychiatric service.

The hospital serves a district with a census population of 208000 aged 16 and over. During the study period there were no identified cases of hospital referrals crossing boundaries either into or out of the district, and we believe this to occur only to a limited extent.

At the time of the study community psychiatric nurses and junior psychiatric doctors saw elective ward referrals during office hours, and there was emergency cover by junior psychiatric doctors for out of hours and $A \& E$ referrals. A consultant was available on call. No systematic psychiatric teaching was available to non-psychiatric medical or nursing staff.

Using a protocol based on reported criteria (Black \& Creed, 1988) we planned to examine prospectively 50 sets of case-notes for patients aged 16 and over presenting with DSH. All identified DSH patients initially presented to $A \& E$, and were traced by a card record system. To avoid bias, staff were not explicitly told when the study was being done.

\section{Findings}

A sample of 57 patients presenting to $A \& E$ was considered between 7 February 1994 and 19 March 1994: an annual rate of 507, or 244 presentations per 100000 of the at-risk population aged 16 and over. Notes with clinical details were found for 50 , with a sex ratio of $25: 25$ and the modal age for men (2635) higher than for women (16-25) (Fig. 1). The seven patients with no notes available comprised four men aged $27,27,36$ and 45 , 


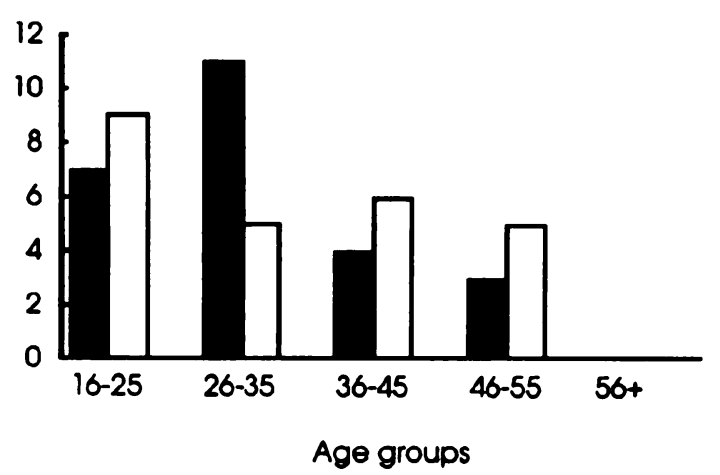

Fig. 1. Gender/age distribution of deliberate self harm in patients aged 16 and over $(n=50)$. Male; $\square$ Female

and three women aged 18, 36 and 42 . They could not be analysed further.

Forty-one (82\%) presented themselves or were referred by family and friends, 47 (94\%) had ingested tablets, one (2\%) was a self-cutter, and two $(4 \%)$ had done both. Ten $(20 \%)$ had an identified history of DSH at the same hospital. Twenty-six (52\%) overdosed on analgesics alone of which $24(48 \%)$ used paracetamol, $20(40 \%)$ took psychotropic drugs either alone or in combination with other drugs, and 18 (36\%) were noted to have ingested alcohol.

Twenty-six (52\%) went home from A\&E, 21 (42\%) were admitted to a medical bed, and three $(6 \%)$ went directly to a psychiatric bed. Nineteen (73\%) of the 26 patients sent home from $A \& E$ had some form of follow-up plan recorded. Psychiatric staff were involved by $A \& E$ in $16(32 \%)$ of all cases.

Of patients referred by $A \& E$ staff or physicians to psychiatry, seven $(14 \%)$ were

Table 1. Quality of records entered into A\&E or medical notes by psychiatric service personnel

\begin{tabular}{lll}
\hline & Frequency & \% of $n=23$ \\
\hline Description of & 11 & 48 \\
DSH & 17 & 74 \\
Precipltating factors & 14 & 61 \\
Social circumstances & 16 & 70 \\
Degree of planning & 2 & 9 \\
Alcohol & 7 & 30 \\
Past psychiatric history & 5 & 22 \\
Family psychlatric history & 14 & 61 \\
Mental state & 15 & 65 \\
Suicide risk & 16 & 70 \\
Written management advice & 18 & 78 \\
Wittten follow-up plan & 18 \\
\hline
\end{tabular}

seen by a junior psychiatrist in A\&E, nine (18\%) were dealt with by telephone advice from the junior psychiatrist on call to $A \& E$; nine (18\%) were seen by a junior psychiatrist and seven (14\%) by a CPN on a medical ward. Five $(10 \%)$ either declined to be seen or discharged themselves before psychiatric personnel arrived. For $13(26 \%)$ we found no evidence of mental health referral.

Seven (14\%) patients were admitted to a psychiatric bed. In only one case was there a record in the non-psychiatric notes of management being discussed with a senior psychiatric colleague. No individuals were detained under the Mental Health Act.

\section{Guality issues}

A\&E notes and medical in-patient notes were examined for any record of the mental state and of the estimated suicide risk recorded by non psychiatric staff. Of the $A \& E$ notes, $(n=50), 30(60 \%)$ included a mental state and $24(48 \%)$ the suicide risk. Of the medical notes $(n=21)$, nine $(43 \%)$ included a mental state, and five $(24 \%)$ the suicide risk.

The quality of information recorded by psychiatric service personnel in A\&E or medical notes $(n=23)$ is shown in Table 1 .

\section{Comment}

DSH rates in Kettering district are consistent with those elsewhere in Europe (Platt, 1992). Some trends reviewed in the introduction were apparent: increasing gender parity, higher peak age among men, and a high rate of paracetamol poisoning, notable because of its toxicity and perhaps reflecting the decreased prescribing of minor tranquillisers.

The A\&E discharge rate of $52 \%$ may rise if acute medical beds are converted into community alternatives, underlining the importance of psychiatric training and provision for A\&E staff. The patchy recording of even rudimentary psychiatric detalls is unjustifiable and may have medico-legal as well as clinical implications.

We believe that deficiencies in services such as that in Kettering can be remedied by high profile, unified and rapidly responsive CLP teams involved in teaching, and appropriately involving non-medical psychiatric staff in high quality DSH assessments. It is essential that innovations in DSH management are evaluated and that service inconsistencies 
are addressed. The expanding demands on mental health services in the community should not be allowed to distract from the management of DSH. The high A\&E discharge rate and erratic quality of case records which we identified indicate the need to give this issue more priority on purchaser agendas.

\section{References}

BLACK, D. \& CREED, F. (1988) Assessment of self-poisoning by psychiatrists and junior medical staff. Journal of the Royal Society of Medicine, 81, 97-99.

ENNIS, J., BARNES, R., KENNEDY, S. et al (1989) Depression in self-harm patients. British Journal of Psychiatry. 154. 41-47.

HAWTON, K. \& FAGG. J. (1992) Trends in deliberate self poisoning and self injury in Oxford, 1976-90. British Medical Journal, 304, 1409-1411.

O'DWYER, F. G., D'Alton, A. \& PEARCE, J. B. (1991) Adolescent self harm patients: audit of assessment in an accident and emergency department. British Medical Journal, 303, 629-630.
OWENS, D. (1990) Self-harm patients not admitted to hospital. Joumal of the Royal College of Physictans of London, 24, 281-283.

-, DENNIS, M., Jones, S. et al (1991) Self-poisoning patients discharged from accident and emergency: risk factors and outcome. Joumal of the Royal College of Physictans of London. 26. 218-222.

- \& JONES. S. J. (1988) The accident and emergency department management of deliberate self-poisoning. British Journal of Psychiatry. 157. 830-833.

PLATT, S. (1992) Parasuicide in Europe: the WHO/EURO multicentre study on parasuicide. 1. Introduction and preliminary analysis for 1989. Acta Psychiatrica Scandinavica, 86, 97-104.

Catherine Gordon, Registrar; and Andrew Blewett, Consultant Psychiatrist, Kettering General Hospital. Correspondence: Dr Andrew Blewett, Kettering District Consultation Liaison Psychiatry Service, The Redcliffe Centre, 51 Hatton Park Road, Wellingborough, Northants NN8 5AH, England

\title{
Management of Violence and Aggression in Health Care
}

\author{
Edited by Brian Kidd and Cameron Stark
}

A multidisciplinary approach to the management of violence, bringing together expert knowledge from medical, nursing, social work and other professionals

Describes ways of assuaging violence both practically and with the use of medication

a Discusses the role of the organisation and ethical considerations

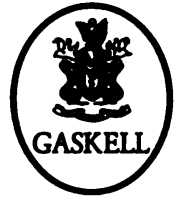

\section{$£ 12.50 \bullet 200 p p . \bullet 1995 \bullet$ ISBN 0902241842}

Available from bookshops and from the Publications Department, Royal College of Psychiatrists, 17 Belgrave Square,

London SW1X 8PG (Tel. 0171-235 2351 extension 146) 